\section{Small hydropower using pump as turbine: an alternative for energy generation in Southern Africa}

\author{
Jinfeng Zhang, Daniel Adu*, Mao Jioyin, \\ Samuel Joe Acquah and Stephen Ntiri Asomani \\ National Research Center of Pumps, Jiangsu University, \\ Zhenjiang 212013, China
}

\begin{abstract}
With the rise in fuel prices as well as energy cost, hydroelectric power is the best alternative for energy generation in rural industries and villages. Small hydropower (SHP) is the largest and oldest source of renewable energy which converts the energy of flowing water into electricity. Small hydroelectric power is entering this field for improving and saving energy in several developing countries through the use of pump in reverse mode as hydraulic turbine; pump as turbine (PAT). It is one of the best alternatives that could meet energy needs by providing electricity in villages and rural settlements as Southern Africa is endowed with a huge untapped SHP energy potentials. In this study, the importance of PAT energy generation for sustainable power, based on its capacity to provide electricity to the rural communities along with contributing to the national grid towards alleviating serious shortage of electricity within Southern African continent, has been discussed. This paper discusses the potentials and the need for SHP development sites in Southern Africa.
\end{abstract}

Keywords: Pressure distribution, pump as turbine, small hydropower, Southern Africa, velocity distribution.

ENERGY contributes a great deal in many areas of life as well as business and serves as a key for a country's development. The world's electricity supply contributes about 20,053 Twh of installed energy, with about $16 \%$ of hydropower in many major countries generating electricity ${ }^{1}$. The advantages of using pump as turbine (PAT) in preference to micro hydropower turbines was outlined by Agarwal $^{2}$. Hydro turbines could potentially be used to recover hydraulic energy dissipated in the hydro turbines network. However, this solution is usually quite extensive and complicated to implement in an existing city network. Another solution is the water network ${ }^{3-5}$ after applying the pump, and turning it into the form of a turbine, commonly referred to as PAT. The pump is a fairly simple machine, cheap (equated to hydro turbine), readily available in the market. Choosing a commercial pump for $\mathrm{PAT}^{6}$ has always been not an easy task because manufacturers do not provide PAT operating curves. Hence studies on PAT depend on the development of inverse process prediction model of centrifugal pumps ${ }^{7-9}$. These

*For correspondence. (e-mail: adudanie139@yahoo.com) techniques are mostly built on geometry, theory and experimental analysis ${ }^{10}$. Africa's hydropower investment channel highlights the potential for renewable energy expansion across the continent. Thus hydroelectric power is an appealing investment in Africa due to this huge potential. Most of the fastest-growing economies globally, are found in the resource-rich African continent. Faster economic growth in the region is because of increased commodity prices. However, access to modern energy is minimal in the region, where over 600 million people live without any access to modern energy especially those in the rural areas. The Democratic Republic of the Congo has a large part of Africa's stated potential. Africa currently carries 40 hydropower projects, of which nine are located in the Democratic Republic of the Congo in addition to the two largest plants, Inga I (354 MW) and Inga II $(1,424 \mathrm{MW})$. The Zambezi river is the most important resource of hydropower and the terrain of Zambia dwell in a larger portion of the river basin, i.e. $41 \%$, compared to the other seven riparian countries. Zambia has reached a hydropower installed capacity of 2,257 MW, based on the accomplishment of the upgraded Lunzua station $(14.8 \mathrm{MW})$ in 2014 , representing about $94 \%$ of the total energy mix of the nation ${ }^{11}$. The total highest small hydropower (SHP) is located in the Eastern African region with a total potential of $6,759 \mathrm{MW}$. With only $216 \mathrm{MW}$ installed capacity, Western Africa has the second highest SHP potential in the continent with $3,113 \mathrm{MW}$, yet the second lowest in installed capacity with only $86.1 \mathrm{MW}$, representing only $3 \%$ of the total potential. The Middle African region, on the other hand, has the largest amount of undeveloped SHP potential. Northern Africa has insufficient potential of $225 \mathrm{MW}$, being one of the lowest in the world, with $112 \mathrm{MW}$ already developed. Africa's SHP can be considered as having a comparatively low level of installed capacity but with high capability for development. The total SHP potential is estimated at $12,197 \mathrm{MW}$ with an installed capacity of $580 \mathrm{MW}$. This indicates that only about $5 \%$ of the potential has been developed. Figures 1 and 2 show the share of SHP installed capacity in Africa (\%) and SHP potential and installed capacity by regions in Africa ${ }^{12}$.

The need for the development of small hydroelectric power stations in Southern African countries is also more. Pump as the turbine is an alternative used to assist in planning a strategy for developing SHP in rural areas in the region. The region is economically under-developed, having few indigenous industries and poor roads. Many areas either have no electricity or are served by the existing old large hydropower plants supported by expensive gas and diesel generated power plants. Energy shortage is a growing economic and social limitation. Limited access to electricity is currently a significant constraint to sustained economic growth across the African continent. In Southern Africa, electricity is scarce ${ }^{13}$. About twothirds of the population, i.e. almost 600 million people 
are without access to electricity because of limited infrastructure for power generation. This lack of modern energy services poses a serious threat to the educational opportunities, economic growth as well as to the health of the people especially school children. Those without electricity often use polluting and expensive lighting sources such as kerosene lamps or candles, the fumes of which can cause severe health problems ${ }^{14}$. Mozambique, on the other hand, has an installed electricity capacity of $2.308 \mathrm{GW}$. The largest hydro potential in the country is

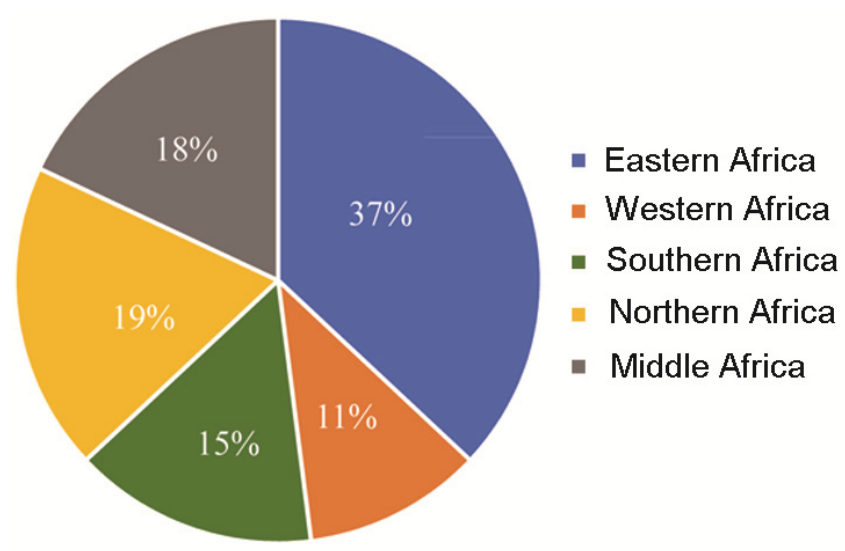

Figure 1. Share of installed small hydropower capacity in Africa (\%).

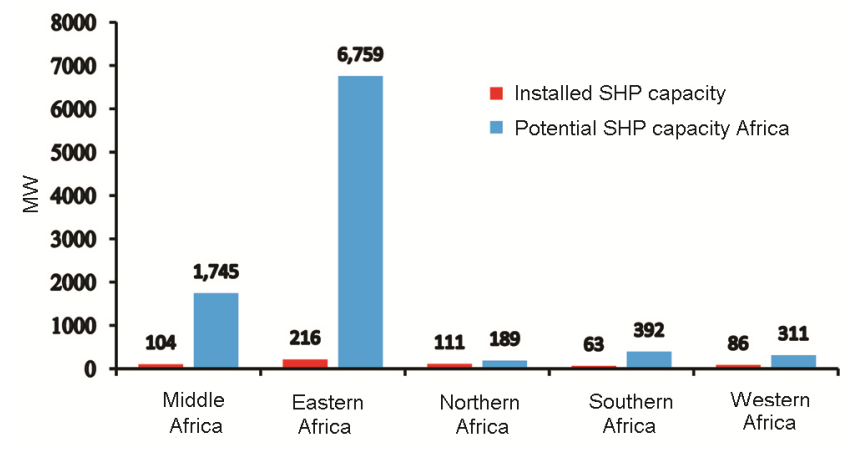

Figure 2. SHP potential and installed capacity by regions in Africa.

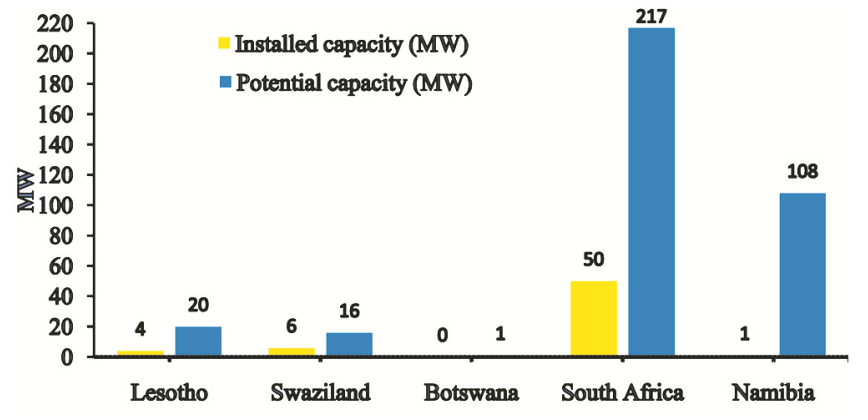

Figure 3. Potential and installed SHP capacities by countries in Southern Africa ${ }^{12}$ depend on the Zambezi river basins Cahora Bassa North and Mphanda Nkuwa. About $80 \%$ of electricity in Swaziland comes from South Africa with the rest $20 \%$ generated from hydropower. Southern African SHP is dominated by South Africa, which covers $80 \%$ of the region's combined installed capacity and $63 \%$ of the estimated potential. But, SHP potential is limited in the region. The combined installed capacity of the region is 62.5 MW out of a total potential of $392 \mathrm{MW}$ which shows that only $16 \%$ has been developed so far. Figure 3 shows the potential and installed SHP capacities (MW) by countries in Southern Africa ${ }^{15-17}$.

A centrifugal pump with six blades was selected for the study. The design parameters and rating of the hydraulic specifications of the model centrifugal pump are given in Table 1 .

The turbulence selected was the $k-\varepsilon$ model with advection scheme set to high resolution. The fluid selected was ideal water at $25^{\circ} \mathrm{C}$. The entire wall surface roughness within the control volume was set to $50 \mu \mathrm{m}$. The inlet and outlet boundary conditions were set to static pressure inlet and mass flow rate outlet. By changing the mass flow rate, performance curves of both the pump mode and PAT were acquired. As the motion of the impeller blades relative to the stationary volute was central to the investigation, the volute and outlet pipe were set in a stationary frame and the impeller was set in a rotary frame. The interfaces between the two stationary components, rotary and stationary, were set to the general grid and rotorstator interface respectively. The boundary condition was set using the 'Boundary' icon $]$; on the toolbar. The inlet and outlet boundary conditions were set by providing $1 \mathrm{~atm}$ total pressure on the casing inlet surface and variable mass flow rate on the impeller outlet surface respectively.

Table 1. Parameters of the model centrifugal pump

\begin{tabular}{llll}
\hline Suction diameter $\left(D_{1}\right)$ & $50 \mathrm{~mm}$ & Flow rate $\left(Q_{\mathrm{d}}\right)$ & $25 \mathrm{~m}^{3} / \mathrm{h}$ \\
Impeller out diameter $\left(D_{2}\right)$ & $160 \mathrm{~mm}$ & Head $\left(H_{\mathrm{d}}\right)$ & $32 \mathrm{~m}$ \\
Impeller out width $\left(b_{2}\right)$ & $6 \mathrm{~mm}$ & Efficiency $\eta$ & $56 \%$ \\
Blade inlet angle $\left(\beta_{1}\right)$ & 24 & & \\
Blade outlet angle $\left(\beta_{2}\right)$ & 30 & & \\
Water temperature $(T)$ & $298.15 \mathrm{~K}$ & Specific speed $\left(n_{\mathrm{s}}\right)$ & 47 \\
Motor power $(P)$ & $3 \mathrm{~kW}$ & Motor speed $(n)$ & $2900 \mathrm{r} / \mathrm{min}$ \\
\hline
\end{tabular}

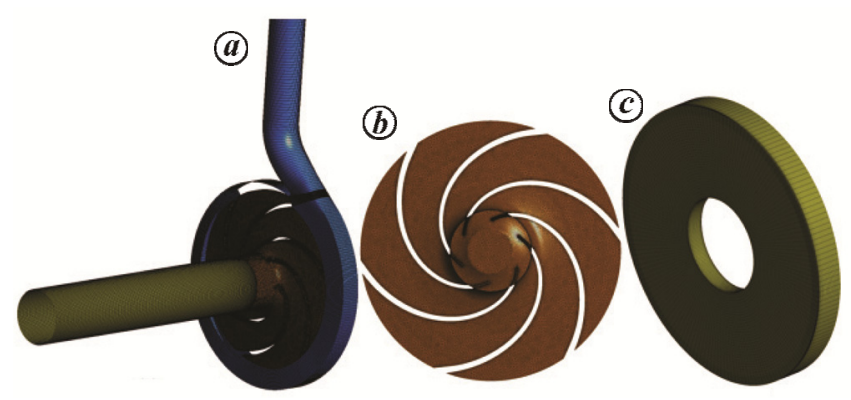

Figure 4. $\boldsymbol{a}$, Complete PAT model; $\boldsymbol{b}$, impeller; $\boldsymbol{c}$, front chamber.

CURRENT SCIENCE, VOL. 118, NO. 3, 10 FEBRUARY 2020 

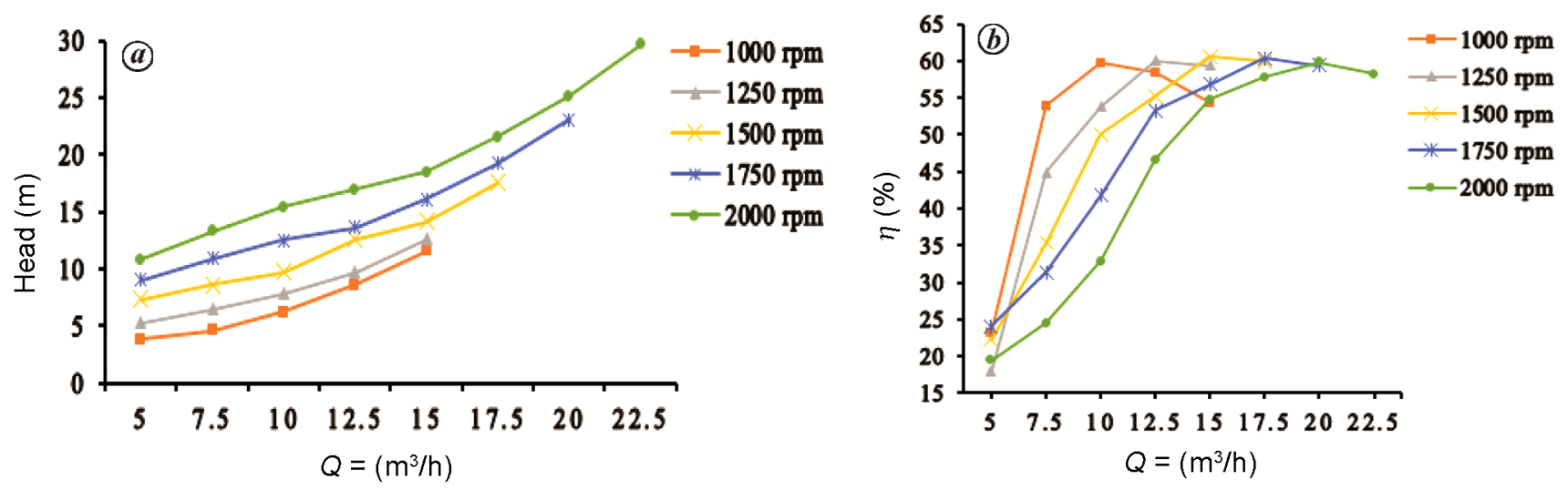

Figure 5. Performance prediction of different rotational speeds in PAT mode (a) head, $(\boldsymbol{b})$ efficiency.
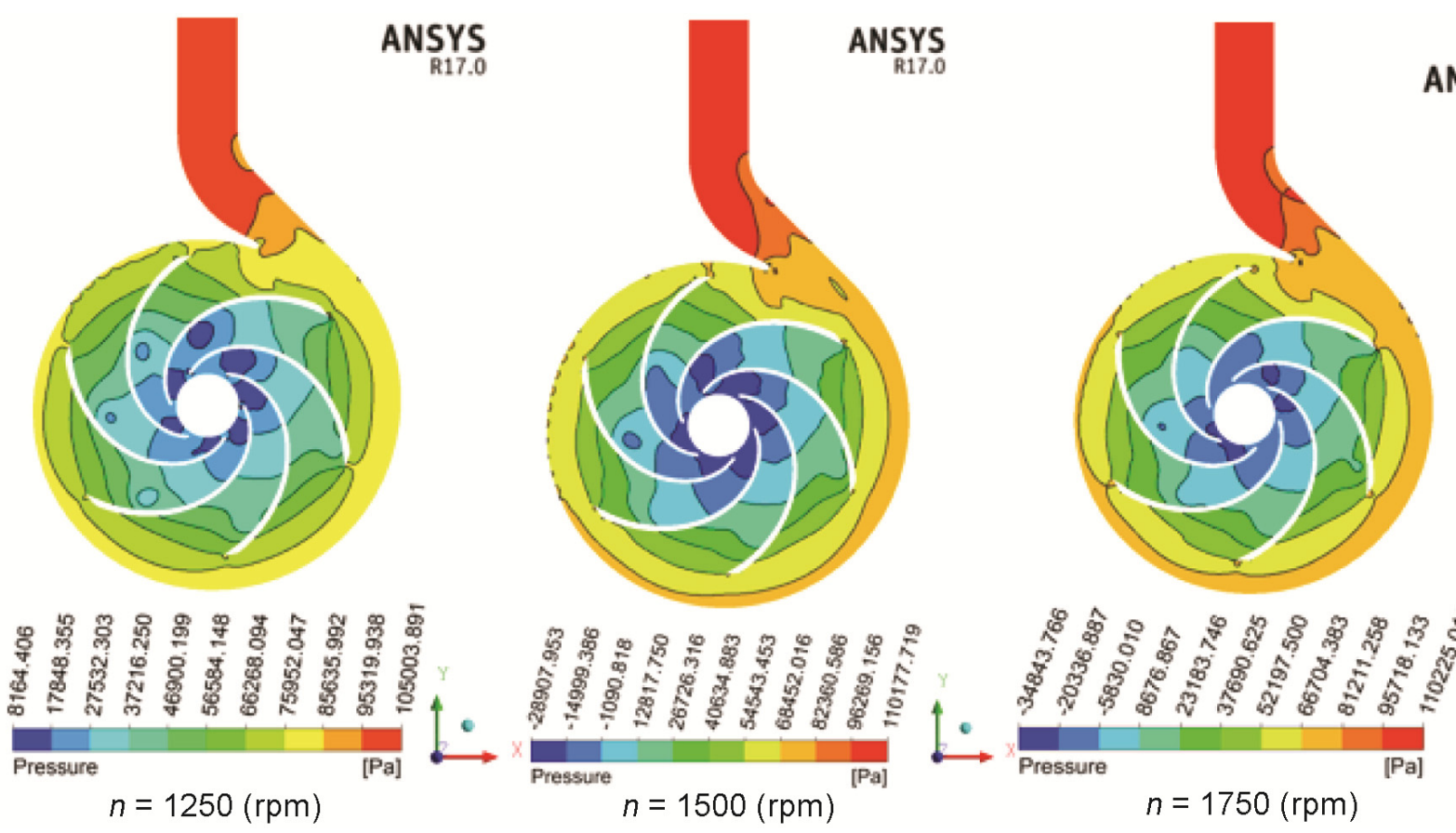

ANSYS

Figure 6. Three-dimensional static pressure distribution for PAT model at different rotational speeds @ $n=$ BEP.

Five per cent medium turbulence intensity for the inlet conditions was considered. A mesh independent analysis was performed and the results showed that when the mesh size was smaller than 1.65, trivial changes occurred in the head and efficiency of the pump. As a result, mesh size of 1.65 was selected for creating the computational domain, bearing in mind the structure of the applied computing, for which Figure 4 shows the mesh of the impeller and volute of the $\mathrm{PAT}^{18}$.

Several numerical simulations were conducted at different rotational speeds between 750 and $2500 \mathrm{rpm}$ with an interval of $250 \mathrm{rpm}$ each in both pump mode and in reverse mode as PAT, using the selected centrifugal pump with six blades, an inlet and outlet impeller with a diameter of 50 and $160 \mathrm{~mm}$ respectively. The aim was to assess the operating range where PAT could effectively perform with adequate efficiency to convert fluid power into mechanical energy. The performance was tested at different rotational speeds since the variation of speed was essential for studying PAT performance at several flow rates and head (Figure $5 a$ ). It was observed that the maximum efficiency from PAT was @ $Q=17.5$ and rotational speed of $1500 \mathrm{rpm}$. Each flow condition was analysed at the best efficiency point (BEP) (Figure $5 b$ ).

Figure 6 shows the static pressure distribution of six impeller blades under different rotational speed conditions of numerical simulation @ $Q=\mathrm{BEP}$, from which the performance changes are shown. The dynamic pressure generated by the rotation of the impeller is converted into a static pressure in the volute, so the maximum static 

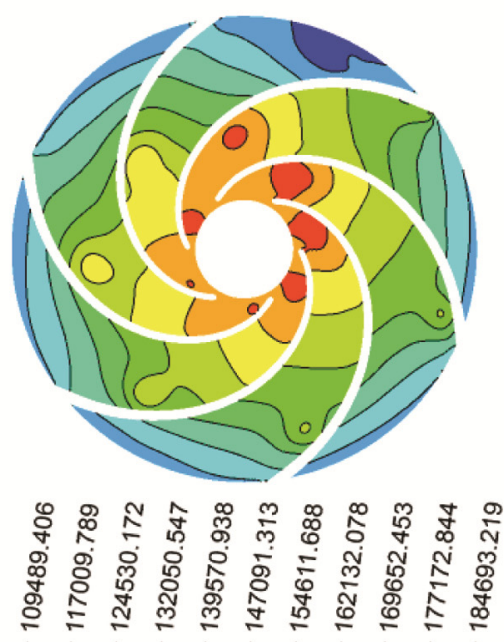

Absolute pressure
[Pa]

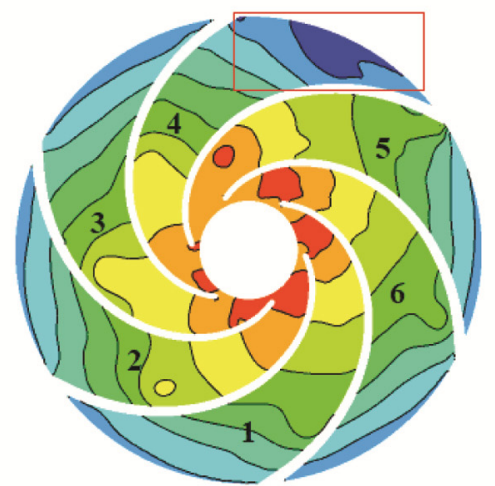

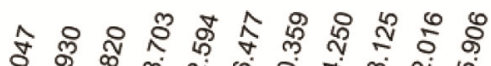

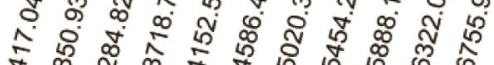

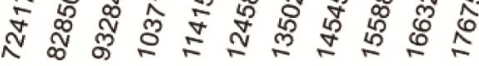

Absolute pressure
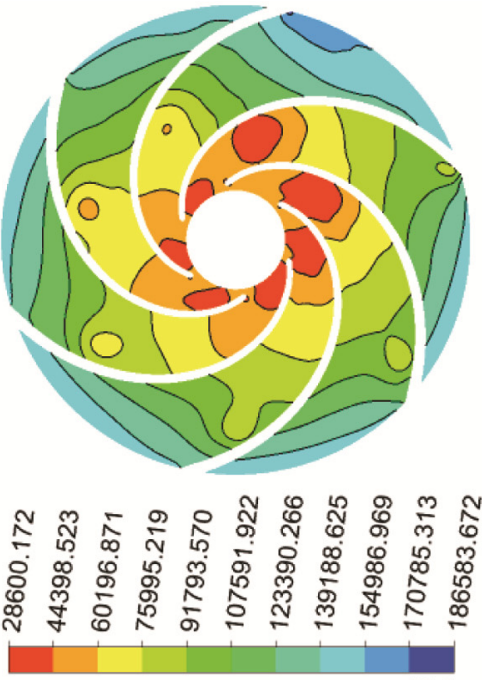

Absolute pressure

Figure 7. Three-dimensional absolute pressure distribution for PAT model at different rotational speeds @ $n=$ BEP.
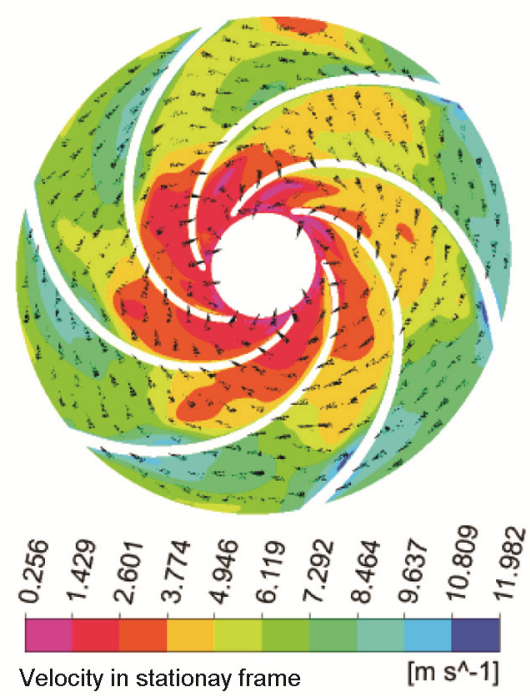
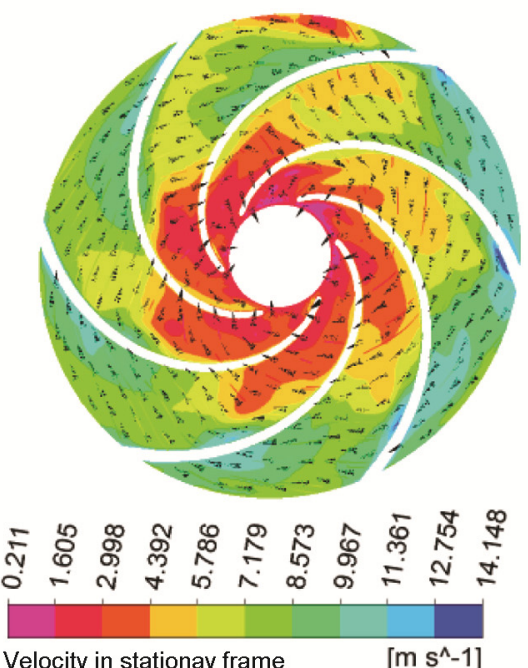
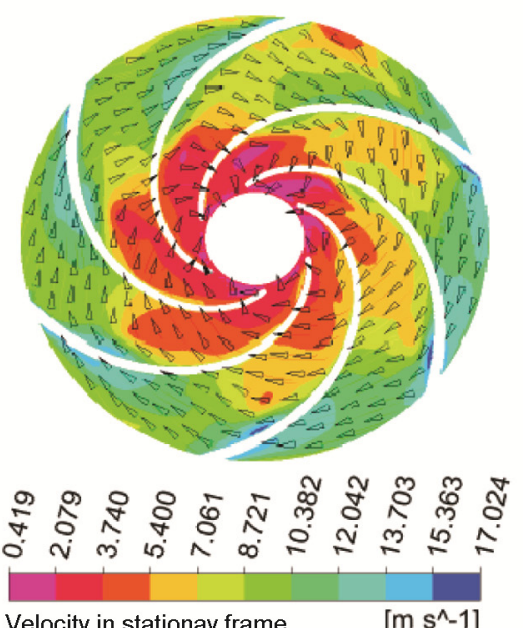

Figure 8. Relative velocity distribution at impeller mid-spans for PAT at different rotational speeds @ $n=$ BEP.

pressure appears at the inlet pipe. It can be observed that a higher pressure exists at the inlet pipe at all operational conditions. However, as rotational speed increases, pressure steadily increases from the suction side to the trailing edge and becomes higher at the trailing edge with low pressure recorded at the suction chamber. Also, as the rotational speed increases, pressure in the suction pipe gradually reduces as shown in Figure 6 with $n=1500 \mathrm{rpm}$ recording the maximum pressure.

Figure 7 represents the graphical presentation of absolute pressure of PAT impeller under different rotational speed working conditions at the BEP. For easy analysis, the impeller blades have been labelled 1-6 according to the direction of impeller rotation. The results show that maximum pressure is located at the trilling edge than the suction side at all conditions. However, $n=1250 \mathrm{rpm}$ shows the highest pressure as seen in Figure 7 and the blade labelled 3 has the highest pressure at the trailing edge. Nevertheless, as the rotational speed increases pressure also increases. It can be observed that pressure increases steadily from the leading edge to the trailing of the impeller as fluid enters the suction chamber of the impeller due to flow acceleration and blade-tongue interaction. This shows that $n=1250$ as the BEP will be appropriate to be used as PAT for power generation.

Figures 8 and 9 show the relative and absolute velocities of selected PAT under different rotational speed conditions at the BEP. As shown in Figure 8, the velocity at the pressure side of the impeller blade is higher than that of the suction side due to velocity slip. Relative velocity 
RESEARCH COMMUNICATIONS
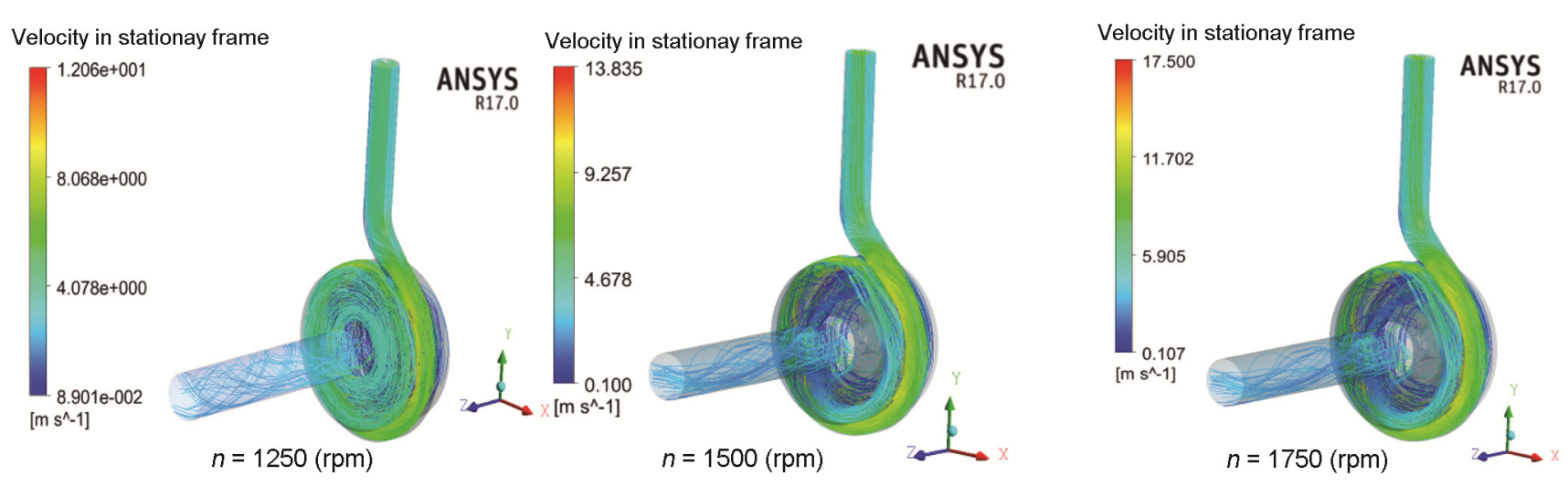

Figure 9. Swirl plots coloured by absolute velocity for PAT model at different rotational speeds @ $n=$ BEP

at the outlet of impeller passage located in front of tongue centrifuge is larger. This is due to the impact of fluid into the volute tongue, resulting in a larger relative velocity; at different rotational speeds @ $Q=$ BEP. Comparing the results, it can be observed that the relative velocity distribution is most uniform and smooth at all rotational conditions. Though recirculation occurs at the pressure surface of the middle blade, the velocity direction of the inlet and outlet remains uniform along the blade. As rotational speed increases, velocity slowly decreases. The axial velocity increases, and closer the flow is to the wall, the more clearer the increase becomes, and even the reflux appears on one side of the wall. At the rotational speed $n=1500 \mathrm{rpm}$, velocity increases steadily which makes the proportion of mainstream area small and disturbs the normal flow. The recirculation swirl enters the outlet pipeline and even blocks the flow passage, causing a substantial increase in energy. With the increase of rotational speed, the swirl becomes more and more influential. At $n=1500 \mathrm{rpm}$, the swirl appears to be more in the discharge pipe. The influence range of recirculation increases and extends to the inlet of the blade which has high interference to the flow. The swirl effect existing in the inlet pipe of the PAT becomes higher for increasing rotational speed. However, at $n=1500 \mathrm{rpm} Q=\mathrm{BEP}$, an uniform flow behaviour exists in the suction pipe and regardless of this swirl occurrence, it becomes stable and faster than the remaining two rotational speed conditions as shown in Figure 9. The swirl at the impeller eye region is caused by acceleration at the leading edge along with the impeller movement.

This study provides information on PAT for SHP generation to overcome electricity crisis in Southern African continent especially in rural areas using PAT. An overview of SHP potentials in the region has been discussed as well as the need for its development through the use of PAT. Several countries have employed PAT for SHP generation in their power stations. It is therefore recommended to be used due to its easy operation and minimal cost for both construction and maintenance. This paper focuses on SHP as a solution to Southern African energy crisis since the use of PAT can help overcome the emerging challenges and promote economic growth in the region. The results from this study revealed that velocity at the pressure side of the impeller blade was higher than the suction side velocity due to velocity slip. Relative velocity at the outlet of impeller passage located in front of tongue centrifuge was larger. This is due to the impact of fluid into the volute tongue, resulting in a relative larger velocity; at different rotational speeds @ $Q=\mathrm{BEP}$. Also, swirl at the impeller eye region is caused by acceleration at the leading edge along with the impeller movement. At the rotational speed $n=1500 \mathrm{rpm}$, velocity increased steadily which makes the proportion of mainstream area small and disturbs the normal flow. The recirculation swirl enters the outlet pipeline and blocks the flow passage, causing a steep increase in energy.

The governments and energy sector management organizations within the region should develop additional SHP stations using PAT to provide electricity for rural settlements and areas without energy access. They are also required to participate in the current programmes of capacity building development of PAT for electricity supply.

1. Jain, S. V. and Patel, R. N., Investigations on pump running in turbine mode: a review of the state-of-the-art. Renew. Sust. Energ. Rev., 2014, 30, 841-868.

2. Derakhshan, S. and Nourbakhsh, A., Experimental study of characteristic curves of centrifugal pumps working as turbines in different specific speeds. Exp. Therm. Fluid Sci., 2008, 32, 800-807.

3. Nautiyal, H. and Varun Kumar, A., Reverse running pumps analytical, experimental and computational study: a review. Renew. Sust. Energ. Rev., 2010, 14, 2059-2067.

4. Dixon, S. L., Fluid Mechanics and Thermodynamics of Turbomachinery, Elsevier, Amsterdam, The Netherlands, 2005, 5th edn.

5. Williams, A. A., The turbine performance of centrifugal pumps: a comparison of prediction methods. Proc. Inst. Mech. Eng. A-J. Pow. Energ., 1994, 208, 59-66.

6. Fernandez, J. et al., Performance of a centrifugal pump running in inverse mode. Proc. Inst. Mech. Eng. A-J. Pow. Energ., 2004, $265-271$. 
7. Singh, P. and Nestmann, F., An optimization routine on a prediction and selection model for the turbine operation of centrifugal pumps. Exp. Therm. Fluid Sci., 2010.

8. Derakhshan, S., Nourbakhsh, A. and Mohammadi, B., Efficiency improvement of centrifugal reverse pumps. ASME J. Fluid. Eng., 2009, 225-237.

9. IEA (International Energy Agency), World Energy Outlook, OECD/IEA, Paris, 2015.

10. ICSHP, World Small Hydropower Development Report, Zhejiang Province International Center on Small Hydro Power 136, Hangzhou, China, 2016.

11. Taele, B. M., Mokhutšoane, L. and Hapazari, I., An overview of small hydropower development in Lesotho: challenges and prospects. Renew. Energ., 2012, 448-452.

12. REEGLE, Country Energy Profile: Mozambique, 2012; http://www.reegle.info/countries/mozambique-energy-profile/MZ

13. Daniel, A. et al., The prospects and submissions for small hydropower development in sub-Saharan African. IOP Conference Series: Earth Environmental Science, 2018, vol. 163, 012022.

14. Chambal, H., Energy Security in Mozambique. Series on Trade and Energy Security - Policy Report 3. International Institute for Sustainable Development, Winnipeg, 2010.

15. Rawal, S. and Kshirsagar, J. T., Numerical simulation on a pump operating in a turbine mode. In Proceedings of the Twenty-Third
International Pump Users' Symposium, Houston, Texas, 2007, p. 21-27.

16. Morros, C. S., Oro, J. M. F. and Diaz, K. M. A., Numerical modelling and flow analysis of a centrifugal pump running as a turbine: unsteady flow structures and its effects on the global performance. Int. J. Num. Methods Fluids, 2011, 65(5), 542-562.

17. Carravetta, A., Fecarotta, O., Martino, R. and Antipodi, L., PAT efficiency variation with design parameters. Proc. Eng., 2014, 70, 285-291.

18. Adu, D. et al., Numerical investigation of transient vortices and turbulent flow behaviour in centrifugal pump operating in reverse mode as Turbine, Materials Science for Energy Technologies, 2018; doi:https://doi.org/10.1016/j.mset.2018.12.002

ACKNOWLEDGEMENTS. This study is financially supported by the National Natural Science Foundation of China (Grant No. 51809121), Natural Science Foundation of Jiangsu Province (Grant No. BK20170548).

Received 19 February 2019; revised accepted 18 September 2019

doi: $10.18520 / \mathrm{cs} / \mathrm{v} 118 / \mathrm{i} 3 / 473-478$ 